\title{
Study sponsorship and the nutrition research agenda: analysis of randomized controlled trials included in systematic reviews of nutrition interventions to address obesity
}

\author{
Alice Fabbri ${ }^{1,2}$, Nicholas Chartres ${ }^{2}$, Gyorgy Scrinis ${ }^{3}$ and Lisa A Bero ${ }^{2, *}$ \\ ${ }^{1}$ Centre of Research in Medical Pharmacology, University of Insubria, Varese, Italy: ${ }^{2}$ Charles Perkins Centre and \\ Faculty of Pharmacy, The University of Sydney, Camperdown NSW 2006, Australia: ${ }^{3}$ Faculty of Veterinary and \\ Agricultural Sciences, The University of Melbourne, Parkville, VIC, Australia
}

Submitted 19 July 2016: Final revision received 12 October 2016: Accepted 18 0ctober 2016: First published online 19 December 2016

\begin{abstract}
Objective: To categorize the research topics covered by a sample of randomized controlled trials (RCT) included in systematic reviews of nutrition interventions to address obesity; to describe their funding sources; and to explore the association between funding sources and nutrition research topics.

Design: Cross-sectional study.

Subjects: RCT included in Cochrane Reviews of nutrition interventions to address obesity and/or overweight.

Results: Two hundred and thirteen RCT from seventeen Cochrane Reviews were included. Funding source and authors' conflicts of interest were disclosed in 82.6 and $29.6 \%$ of the studies, respectively. RCT were more likely to test an intervention to manipulate nutrients in the context of reduced energy intake ( $44.2 \%$ of studies) than food-level (11.3\%) and dietary pattern-level (0.9\%) interventions. Most of the food industry-sponsored studies focused on interventions involving manipulations of specific nutrients (66.7\%). Only $33.1 \%$ of the industry-funded studies addressed dietary behaviours compared with $66.9 \%$ of the non-industry-funded ones $(P=0 \cdot 002)$. The level of food processing was poorly considered across all funding sources.

Conclusions: The predominance of RCT examining nutrient-specific questions could limit the public health relevance of rigorous evidence available for systematic reviews and dietary guidelines.
\end{abstract}

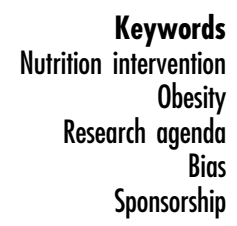

Public health nutrition policies are essential for controlling the epidemics of obesity, CVD and type 2 diabetes ${ }^{(1,2)}$. Many political, social and economic factors contribute to dietary guideline and nutrition policy development, but a fundamental principle is that they should be informed by relevant, rigorous evidence ${ }^{(3)}$. Systematic reviews have been extensively used as the evidence base for the development of both clinical and public health guidelines $^{(4)}$. In recent years the use of systematic reviews has also become increasingly common to address nutrition-related questions. The most recent national dietary guidelines in the USA and Australia were based on systematic reviews and Food Standards Australia New Zealand currently requires systematic reviews to support high-level health claims on food labels ${ }^{(5-7)}$. The Cochrane Collaboration has launched the Cochrane Nutrition Field to increase the number, quality and relevance of Cochrane Nutrition Reviews ${ }^{(8)}$.
A major limitation of the growing use of systematic reviews for the development of guidelines, policies and regulations is that their scope is limited by the topics of the original research studies available to be included in the reviews. In addition, systematic reviews are often limited to randomized controlled trials (RCT). This could lead to systematic reviews that are not relevant or representative of the target population for the guidelines ${ }^{(9)}$.

The characteristics of the research agenda (namely the questions being studied) are particularly important in nutrition because the questions asked, such as nutrientspecific questions, could produce evidence that is disproportionately focused on certain policy solutions, such as food fortification ${ }^{(10)}$. This research could then distract from considering other possible public health solutions, such as taxes or regulating food advertising or processed food commodities. Studies to address complex policy questions relevant to public health nutrition also 
present methodological challenges that may contribute to them being less studied ${ }^{(11)}$.

Several actors (industry, government and non-profit stakeholders) have the potential to affect the policy-making process by influencing the nutrition research agenda ${ }^{(12,13)}$. Data from other sectors (e.g. tobacco, pharmaceuticals) has previously demonstrated biases in the design, conduct and publication of research that are related to funding sources and investigators' conflicts of interest ${ }^{(14-16)}$. Corporate interests can manipulate the research agenda by funding research that supports their position and suppressing research that does not ${ }^{(17)}$. For example, the tobacco industry undermined the research agenda on the health effects of second-hand smoke by funding studies suggesting that other components of indoor air were more harmful than tobacco ${ }^{(14)}$. Echoing tactics used by the tobacco industry, the sugar industry has influenced the dental research agenda 'as part of a strategy to deflect attention away from sugar restriction as a means to control caries, ${ }^{,(18)}$.

Despite some case studies documenting discrepancies in the design and conclusions of research sponsored by the food industry compared with other funders ${ }^{(19-22)}$, a systematic analysis examining whether funding sources influence the nutrition research agenda has not been done. Analysing the relationship between funders and the nutrition research agenda could assist both researchers and policy makers in understanding whether an entire area of research has been funded only by stakeholders with conflicts of interest and in identifying new or neglected areas which may require further investigation.

Therefore the objectives of the present study were to:

1. categorize the research topics covered by a sample of RCT included in systematic reviews of nutrition interventions to address obesity;

2. describe their funding sources; and

3. explore the association between funding sources and nutrition research topics.

\section{Methods}

\section{Study selection}

We analysed RCT that were included in Cochrane Reviews of nutrition interventions aimed at reducing obesity. Cochrane Reviews cover a broad range of clinical and public health interventions and have been used to support the WHO Nutrition Guidelines Programme ${ }^{(8)}$. We searched the Cochrane Database of Systematic Reviews on 24 July 2015 using the following broad search strategy: obesity AND (nutrition* OR diet*), to identify reviews that included nutrition interventions to prevent or reduce obesity. We focused on obesity because this is a complex condition that could be addressed by a variety of interventions ranging from patient-specific to system-wide interventions ${ }^{(23)}$. Two investigators screened the retrieved records for obvious exclusions. We excluded reviews that did not include studies of nutrition interventions or did not have measures of obesity or overweight as primary or secondary outcomes (see online supplementary material, Supplemental Tables 1 and 2 for lists of included and excluded Cochrane Reviews). Since the emphasis of Cochrane Reviews has been on the identification and assessment of RCT, we then included all the RCT that were included in the selected Cochrane Reviews if they investigated nutrition interventions or a combination of nutrition and non-nutrition interventions (e.g. drug, physical activity). For this purpose, we defined nutrition interventions as all dietary interventions that modify energy, dietary patterns, whole food and/or nutrient intake. We included studies where the primary or secondary outcomes were BMI or other measures of overweight and obesity (e.g. body composition, waist-to-hip ratio).

\section{Data extraction}

The full text was retrieved for each included RCT. If the same study appeared in more than one Cochrane Review, we included it only once. The following data were collected from each RCT publication.

1. Study characteristics: target group, location, year of publication.

2. Disclosed funding source(s): these were classified as food industry, pharmaceutical industry, other for-profit entities, governmental agencies, not for profit, mixed funding sources, unknown (when the funding source was disclosed in the article, but information about the sponsor could not be retrieved from the Internet) or no funding disclosed.

3. Disclosure of investigators' conflicts of interest.

4. Research topics classified according to the categories described below.

The taxonomy we used to code research topics was inspired by a framework for food classification ${ }^{(24)}$ that was informed by iterative coding of a sample of nutrition intervention studies and by input from a multidisciplinary group of public health researchers, physicians, dieticians, nutritionists and social scientists. We coded research topics by: (i) the level of dietary composition; (ii) level of food processing; and (iii) dietary behaviours. Each category was coded as 'yes' or 'no'. The coding categories are described in more detail below.

\section{Level of dietary composition}

This categorization is based on the differentiation between the three levels of dietary composition discussed in the nutrition literature: the nutrient level, the food level and the dietary pattern level ${ }^{(24,25)}$. Since our sample included nutrition interventions to address obesity, we expected most of the studies to have an energy component, often without the study specifying the restriction of one nutrient over another to achieve energy restriction; therefore the additional 
category of energy was added to the initial taxonomy. Specifically, we assessed whether the intervention described in the article focused on

- energy level: focus on energy restriction;

- nutrient level: focus on changing intake of specific nutrients such as fat, protein, carbohydrates, etc.;

- food level: focus on changing consumption of a single food or food product, food groups or food combinations, such as vegetables, fruit, grain foods, meats, fish, eggs, or processed foods such as sugar-sweetened beverages, high-energy snacks, fast foods, etc.;

- dietary pattern level: focus on the overall dietary pattern or cuisine, for example the Mediterranean diet; or

- not applicable: when there was not enough information in the article or the intervention did not fit in any of the above categories.

Our a priori hypothesis was that while a focus on the nutrient level is a common feature of nutrition research ${ }^{(26)}$, the food industry has supported nutrient-level studies as a means of generating evidence to support its nutritional claims on food products ${ }^{(24)}$.

\section{Level of food processing}

We determined whether the nutrition intervention studied in each RCT mentioned food processing, namely the type, level and intensity of technological intervention used in the production of food ${ }^{(24)}$. A study was rated as 'yes' if it mentioned highly processed foods, defined as foods that are constructed primarily out of processed-reconstituted and refined-extracted materials, either specifically (e.g. sugar-sweetened beverages) or descriptively (e.g. foods high in energy with low nutrient density), or as part of a complex intervention (e.g. mentioning limiting consumption of high-energy snacks and fast foods on one part of a nine-part weight-reduction intervention). The initial version of our taxonomy included the multiple levels of processing: whole foods, refined-processed foods and processedreconstituted foods. However, when we pilot tested the taxonomy, we found that some studies defined the level of processing very poorly and many of the complex interventions included all three levels of food processing. Therefore, we modified the initial taxonomy to code for the mention of highly processed foods or not.

Our a priori hypothesis was that there is currently a lack of studies focusing on the evaluation of nutrients, foods and dietary patterns in terms of the levels of processing and that the food industry is not funding this kind of research ${ }^{(24,27)}$.

\section{Dietary behaviours}

A study was coded as 'yes' for dietary behaviours if the nutrition intervention addressed dietary behaviours (e.g. portion size, menu planning and cooking style, timing of meals, eating while watching television, meal skipping, self-control/self-monitoring of food intake). Our a priori hypothesis was that the food industry is less likely to fund studies aimed at improving dietary behaviours.

\section{Double coding}

For the analysis of the nutrition research topics, 30\% of the publications were randomly selected to be coded independently by two reviewers and any disagreement was resolved by consensus.

On average, the percentage of agreement between the two coders was $91.4 \%$.

\section{Analysis}

Categorical variables were described using frequency tables. Cross-tabulations were performed for evaluating possible associations between the funding sources and the research topics using the $\chi^{2}$ test. All analyses were performed using the statistical software package IBM SPSS Statistics Version 22.0.

\section{Results}

\section{Study selection}

The electronic database search yielded forty-four Cochrane Reviews (Fig. 1). Of these, twenty-seven were excluded because they did not match our inclusion criteria (online supplementary material, Supplemental Table 2).

Of the 272 RCT contained in the seventeen remaining Cochrane Reviews (online supplementary material, Supplemental Table 1), fifty-nine were excluded because they did not match the inclusion criteria (Fig. 1). Five studies appeared in more than one Cochrane Review and they were each included once. The 213 included RCT evaluated a broad range of nutrition interventions targeting children/ adolescents ( $n$ 25; 11.7\%), adults ( $n$ 114; 53.5\%) or both ( $n 74 ; 34.7 \%)$. The range of publication dates was 1978-2013 and $31.5 \%$ of the included studies were published before 2000. The majority of the RCT were conducted in the Americas; US-based studies represented 55.4\% ( $n$ 118) of the total sample (Table 1).

\section{Funding disclosure}

Of the 213 included RCT, 82.6\% ( $n$ 176) disclosed their funding source. Of these, 175 RCT disclosed the presence of one or multiple sponsors, while in one study the investigators stated they received no funding for their work. Of the 175 RCT that disclosed having a sponsor, 37.1\% ( $n$ 65) were funded by governmental or intergovernmental agencies, while food industry sponsorship (alone or with other sponsors) was disclosed in $13.7 \%$ ( $n$ 24) of the studies (Table 2). The disclosure rate increased over time: from $74.2 \%$ for the studies published before the year 2000 , to $85.3 \%$ for the ones published between 2000 and 2009, to $93.3 \%$ for the ones published after 2009. We chose these cut-offs because of the increasing attention that has been 


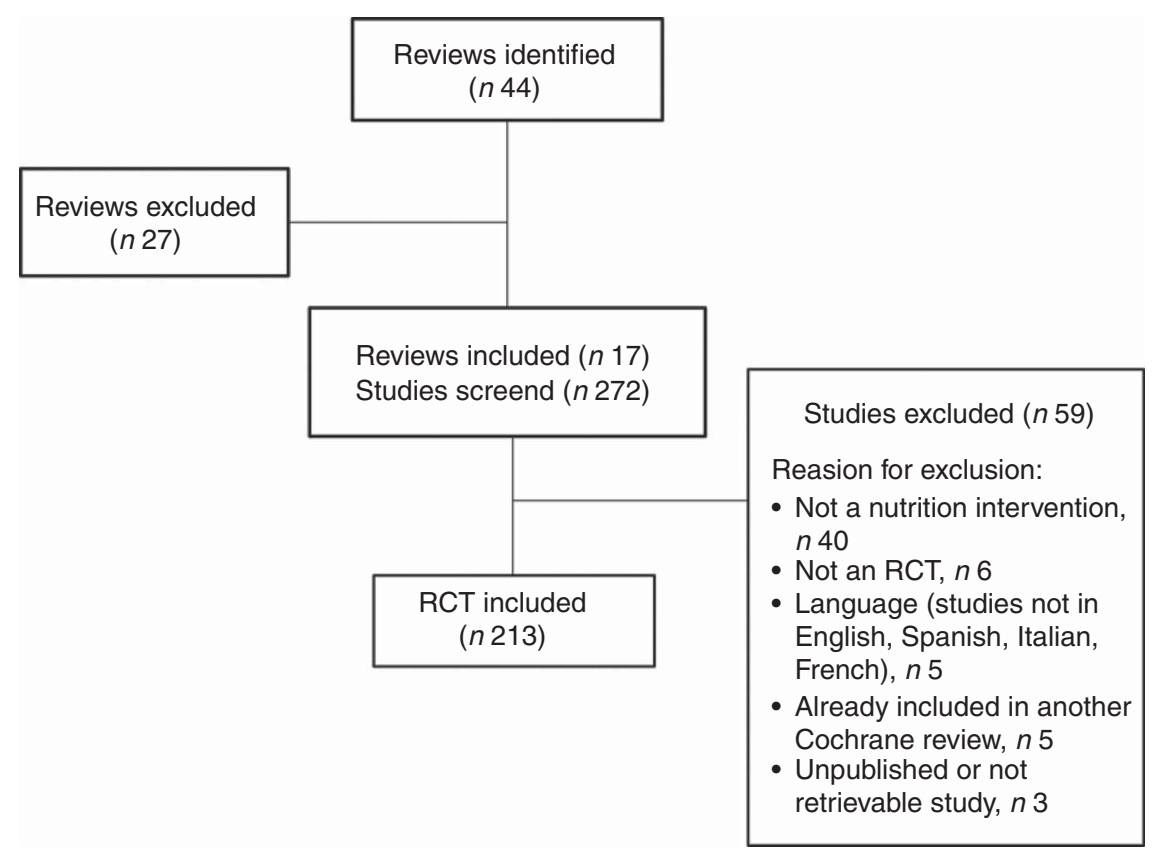

Fig. 1 Flowchart of study selection (RCT, randomized controlled trial)

Table 1 Location of study site by WHO Region in the analysed randomized controlled trials included in seventeen systematic reviews of nutrition interventions to address obesity, 1978-2013 (n 213)

\begin{tabular}{lrr}
\hline Location & $n$ & $\%$ \\
\hline Africa & 1 & 0.5 \\
Americas & 126 & 59.1 \\
Europe & 60 & 28.1 \\
Eastern Mediterranean & 0 & 0.0 \\
South-East Asia & 1 & 0.5 \\
Western Pacific & 23 & 10.8 \\
Not clear & 2 & 0.9 \\
Total & 213 & 100.0 \\
\hline
\end{tabular}

Table 2 Categories of funding sources for studies disclosing a sponsor in the analysed randomized controlled trials included in seventeen systematic reviews of nutrition interventions to address obesity, 1978-2012 (n 175)

\begin{tabular}{lrr}
\hline Funding source & $n$ & $\%$ \\
\hline Governmental agencies & 65 & 37.1 \\
Non-profit & 28 & 16.0 \\
Pharmaceutical industry & 12 & 6.9 \\
Food industry & 8 & 4.6 \\
Mixed funding sources (without industry) & 34 & 19.4 \\
Mixed funding sources (with food industry) & 16 & 9.1 \\
Mixed funding sources (with pharmaceutical industry) & 9 & 5.1 \\
Unknown & 3 & $1 \cdot 7$ \\
Total & 175 & 100.0 \\
\end{tabular}

given to the need for transparency in recent years and the consequent adoption of disclosure policies by most scientific journals ${ }^{(28,29)}$.

\section{Investigators' conflicts of interest disclosure}

Of the 213 included RCT, 70.4\% ( $n$ 150) did not contain a conflicts of interest disclosure. In twenty-two studies (10.3\%) the authors disclosed financial conflicts of interest, in one study $(0.5 \%)$ the authors disclosed non-financial conflicts of interest, and in forty (18.8\%) the authors stated they had no financial conflicts of interest. The disclosure rate increased over time. Conflicts of interest disclosure was completely absent in the papers published before the year 2000, the disclosure rate was $39.0 \%$ in the papers published between 2000 and 2009, and 66.7\% in the papers published after 2009.

\section{Research topics}

Table 3 shows the nutrition research topics studied in the included RCT. Most of the RCT studied interventions that involved a combination of energy-, nutrient- and food-level approaches. As anticipated for interventions to reduce obesity, most trials aimed to restrict energy intake and vary the dietary composition, while sixteen $(7.5 \%)$ varied energy intake only. Ninety-four trials (44.2\%) tested interventions focused on specific nutrients, fifty-eight (27.2\%) analysed a combination of nutrients and foods, while only twenty-four (11.3\%) analysed whole foods. Only two trials (0.9\%) included an analysis of dietary patterns (e.g. Mediterranean diet). Highly processed foods were considered in less than one-third of the tested interventions and slightly more than half the interventions considered dietary behaviours such as portion size or timing of meals.

\section{Research topics by funding sources}

Table 4 shows the results of the analysis of nutrition research topics by funding source. To test our hypotheses that research with a focus on nutrients has been supported by the food industry while research including an analysis of food processing has not been supported by the food 
Table 3 Nutrition research topics in the analysed randomized controlled trials included in seventeen systematic reviews of nutrition interventions to address obesity, 1978-2013 (n 213)

\begin{tabular}{lrr}
\hline Research topic & $n$ & $\%$ \\
\hline Level of dietary composition & 16 & $7 \cdot 5$ \\
$\quad$ Energy & 94 & $44 \cdot 2$ \\
$\quad$ Nutrient $(n$ 21) & & \\
Nutrient +Energy $(n$ 73) & 24 & $11 \cdot 3$ \\
Food $(n$ 16) & & \\
Food +Energy $(n$ 8) & 58 & $27 \cdot 2$ \\
$\quad$ Nutrient/Food $(n$ 24) & & \\
Nutrient/Food +Energy $(n$ 34) & 2 & $0 \cdot 9$ \\
Dietary pattern & 19 & $8 \cdot 9$ \\
$\quad$ Not applicable & 57 & $26 \cdot 8$ \\
Level of food processing & 156 & $73 \cdot 2$ \\
$\quad$ Yes & 121 & $56 \cdot 8$ \\
$\quad$ No & 92 & $43 \cdot 2$ \\
Dietary behaviours & & \\
Yes &
\end{tabular}

Table 4 Research topics by funding source* in the analysed randomized controlled trials included in seventeen systematic reviews of nutrition interventions to address obesity, 1978-2012 ( $n$ 151)

\begin{tabular}{|c|c|c|c|c|c|}
\hline \multirow[b]{2}{*}{ Research topic } & \multicolumn{2}{|c|}{$\begin{array}{l}\text { Food industry } \\
\qquad(n 24)\end{array}$} & \multicolumn{2}{|c|}{$\begin{array}{c}\text { Non-food } \\
\text { industry }(n 127)\end{array}$} & \multirow[b]{2}{*}{$P$ value } \\
\hline & $n$ & $\%$ & $n$ & $\%$ & \\
\hline \multicolumn{6}{|l|}{ Level of dietary composition } \\
\hline Energy & 2 & $8 \cdot 3$ & 10 & 7.9 & 0.083 \\
\hline $\begin{array}{l}\text { Nutrient } \\
\text { Nutrient + Energy }\end{array}$ & 16 & $66 \cdot 7$ & 45 & $35 \cdot 4$ & \\
\hline $\begin{array}{l}\text { Food } \\
\text { Food + Energy }\end{array}$ & 1 & $4 \cdot 2$ & 17 & 13.4 & \\
\hline $\begin{array}{l}\text { Nutrient/Food } \\
\text { Nutrient/Food + Energy }\end{array}$ & 5 & $20 \cdot 8$ & 42 & $33 \cdot 1$ & \\
\hline Dietary pattern & 0 & 0.0 & 2 & 1.6 & \\
\hline Not applicable & 0 & 0.0 & 11 & $8 \cdot 7$ & \\
\hline \multicolumn{6}{|l|}{ Level of food processing } \\
\hline Yes & 6 & $25 \cdot 0$ & 40 & 31.5 & 0.526 \\
\hline No & 18 & $75 \cdot 0$ & 87 & 68.5 & \\
\hline \multicolumn{6}{|l|}{ Dietary behaviours } \\
\hline Yes & 8 & 33.3 & 85 & $66 \cdot 9$ & 0.002 \\
\hline No & 16 & $66 \cdot 7$ & 42 & $33 \cdot 1$ & \\
\hline
\end{tabular}

Column percentages are calculated.

${ }^{*}$ The food industry-sponsored category includes studies sponsored solely by the food industry or with mixed food industry and other funding; the non-food industry category includes studies funded by governmental agencies, nonprofit sector and mixed funding sources without the presence of food industry.

industry, we compared the research topics of food industry-sponsored $v$. non-food industry-sponsored studies. The food industry sponsorship category includes studies sponsored solely by the food industry or with mixed food industry and other funding ( $n$ 24). The non-food industry category includes studies funded by governmental agencies, non-profit sector and mixed funding sources without the presence of food industry ( $n$ 127). We did not include in this analysis the trials funded by pharmaceutical companies and the ones with undisclosed funding sources, therefore the total number of included RCT is 151.

As shown in Table 4, most of the food industry-sponsored studies focused on interventions involving manipulations of specific nutrients (66.7\%). The non-food industry-funded trials addressed different levels of dietary composition, including whole foods and a combination of foods and nutrients. The dietary pattern level was poorly considered across all funding sources. There was no statistically significant association between the research sponsorship and the different levels of dietary composition addressed in the included RCT ( $\chi^{2}$ test: $P=0 \cdot 083$ ). With regard to food processing, only $25.0 \%$ ( $n$ 6) of industry-funded studies and $31.5 \%$ ( $n$ 40) of the non-industry-funded interventions mentioned the issue of highly processed foods. No statistically significant differences were observed between the two categories of funding sources $\left(\chi^{2}\right.$ test: $\left.P=0.526\right)$. Finally, non-industry-funded trials were more likely to address dietary behaviours compared with food industry-sponsored studies $\left(\chi^{2}\right.$ test: $\left.P=0 \cdot 002\right)$.

\section{Discussion}

\section{The nutrition research agenda}

Our findings show a gap in the research topics covered by RCT of nutrition intervention studies. The majority of the included RCT involved some manipulation of nutrients in a context of a reduced energy intake, while there was less study of food-level and dietary pattern-level interventions. A reductive focus on nutrients has been a feature of nutrition research in the past decades ${ }^{(25,26,30)}$. A fundamental characteristic of nutritional reductionism is that the role of nutrients has often been interpreted outside the context of the foods, dietary patterns, and broader social contexts in which they are embedded' ${ }^{(24)}$. While recognizing the importance of understanding the biological effect of nutrients, a nutrient approach is likely to offer only a decontextualized, context-free interpretation of the complex relationship between diet and health outcomes. In this regard, some researchers have already called for an alternative research approach, namely a 'top-down' approach that works 'from complex to simple(26), starting from the dietary pattern level and working backwards to the nutrient level ${ }^{(30)}$. In addition, nutritional ecology studies suggest that powerful insights into the causes of obesity can be gained by studying the interactive rather than the independent effects of nutrients ${ }^{(31)}$. Since people eat foods and not isolated nutrients, dietary guidelines and policies built upon research on foods and dietary patterns might more effectively inform people's behaviours and food choices ${ }^{(25,32)}$.

Our findings also suggest that the research agenda may be influenced by industry interests. We found that most of the food industry-sponsored studies focused on interventions involving manipulations of specific nutrients. Some researchers have argued that in response to concerns about 
how diet contributes to the obesity epidemic, the food manufacturing industry has responded by emphasizing the benefits of particular nutrients in their foods ${ }^{(24)}$. Thus, the food industry may have an incentive to fund research showing that certain types of nutrients are beneficial to health. A focus on nutrients - rather than on dietary patterns or interactions among nutrients within foods and within the body - may produce evidence that will allow the food industry to market highly processed foods using nutrient content claims (e.g. functional foods). For example, a systematic review of highly processed breakfast cereals commissioned by the Australian Breakfast Cereal Manufacturers Forum suggests that cereal consumption is associated with lower rates of diabetes and $\mathrm{CVD}^{(33)}$ and cereals are often advertised as having beneficial health outcomes ${ }^{(24)}$.

Despite the evidence that processed foods are a significant driver in the global rise of overweight, obesity and associated diseases ${ }^{(13,34)}$, our findings showed that little research describes the level of processing of the food being studied. This lack of data cannot provide the evidence needed to inform guidelines and policies that could limit consumption of processed foods. Food classifications have often grouped foods according to their nutrient profile or unprocessed food groups (e.g. fruits, vegetables), whereas the nature and extent of food processing should also be included as part of the description of the intervention ${ }^{(35)}$. This lack of categorization by level of food processing has led to examples of processed foods such as ketchup being classified as a school-lunch vegetable in the USA ${ }^{(36)}$.

Our findings identified that food industry-sponsored studies were significantly less likely to address dietary behaviours as part of an intervention compared with nonfood industry-sponsored studies. While nutrition-specific interventions are necessary to measure the effect of specific nutrients, there is evidence to suggest that they fail to address the underlying complexities of what is required to achieve and maintain weight loss in obese populations ${ }^{(37,38)}$. In a food system where dietary intake is no longer influenced primarily by food availability, a research agenda that continues to mostly examine nutrients and foods in isolation and not in the context of dietary and other behaviours will likely fail to ease the growing burden of obesity.

Sponsors' interests are not the only drivers of a nutrient focus. Studies to address complex nutrition policy problems present enduring challenges that may contribute to them receiving less attention and funding ${ }^{(11)}$. Moreover, the current process for evidence synthesis and translation itself tends to favour a nutrient-oriented approach. A recent study has shown that in the field of undernutrition there are significantly more systematic reviews, guidelines and policy statements related to nutrition-specific interventions (e.g. fortification and supplementation) compared with nutrition-sensitive interventions that could instead address the underlying causes of the problem ${ }^{(10)}$.

Finally, our results show a gap in the research topics covered by RCT of nutrition interventions to decrease obesity, but diet-disease relationships are often evaluated using non-randomized studies and many dietary guidelines are currently supported by evidence from observational studies $^{(6)}$. The Cochrane Collaboration is currently exploring evidence synthesis methods that are needed to address complex nutrition interventions which are often studied using observational research ${ }^{(8)}$. Therefore, further research is needed to evaluate whether the gaps in the topics covered by RCT included in systematic reviews apply also to non-randomized studies.

\section{Reporting of funding source and investigators' conflicts of interest}

We found that about $20 \%$ of the studies did not report funding sources, although disclosure rates increased over time. The low proportion of food industry-sponsored studies in our sample could be due to a lack of reporting of industry sponsorship. This phenomenon has already been reported in other fields; for example, the tobacco industry funded institutes and organizations that hid the true extent of industry involvement in their projects ${ }^{(39)}$.

We also found a low rate of reporting of investigators' conflicts of interest. Although a recent study found that all core clinical journals require disclosure of author financial conflicts of interest ${ }^{(40)}$, these disclosure policies are still not enforced across all journals. The failure to comply with the current conflicts of interest disclosure requirements has been reported in several studies ${ }^{(41-43)}$; therefore it is likely that the disclosures we relied on did not give an accurate assessment of authors' conflicts of interest.

A recent call for disclosure of funding sources and authors' conflicts of interest in all abstracts listed in PubMed could improve reporting across all journals ${ }^{(44)}$. If funding sources and investigator conflicts of interest are not reported or only partially reported, differences in the design, conduct and publication of industry- compared with non-industry-sponsored studies cannot be empirically investigated. Readers will not be able to determine whether an area of research has been funded only by certain stakeholders and might be left unsure about how to interpret the likelihood of bias related to funding source ${ }^{(45)}$. This reporting gap may also have important research and policy implications by making it difficult to estimate the impact of funding sources on the studies included in systematic reviews and, consequently, public health guidelines and regulations. A recent revision of the methodological standards for Cochrane Reviews requires that funding sources for included studies be listed in the included studies table ${ }^{(46)}$. However, most Cochrane Reviews do not currently contain these disclosures ${ }^{(45)}$.

\section{Limitations}

Our study has several limitations. First, we searched the Cochrane Database of Systematic Reviews using the following terms: obesity AND (nutrition* OR diet*). It is 
possible that this search strategy might have missed potentially eligible reviews. However, the search strategy is very broad and the large number of reviews identified that did not meet our inclusion criteria suggests that our initial search was sensitive rather than specific.

Another limitation is that we analysed only RCT included in Cochrane Reviews. However, Cochrane Reviews cover a broad range of interventions targeted at adults, children or both, involve a comprehensive search for evidence, and their topics are often driven by the availability of original research. Thus, the studies included in the Cochrane Reviews are likely a good representation of the type of RCT that have been conducted on nutrition interventions to reduce obesity. In addition, we focused on obesity because it is a complex health condition that could be addressed by a wide variety of nutrition interventions. Our findings may be different if we focused on other harm outcomes, such as CVD, or the beneficial effects of foods.

Another challenge of the present study was the development of a taxonomy able to capture the complexity of research topics examined in nutrition intervention studies. Moreover, we relied only on the intervention description provided in the publications. Sometimes the quality of the description was poor or not detailed, so we might have missed important aspects of the intervention. Accurate and complete descriptions of complex interventions are crucial to ensuring not only the evaluation of interventions but also their replicability ${ }^{(47)}$.

The low proportion of food industry-sponsored studies compared with non-food industry-sponsored studies may explain why we did not observe statistically significant differences between funding sources. Food industry sponsorship may have been under-reported.

\section{Conclusions}

Our findings show a gap in the research topics covered by RCT of nutrition interventions to address obesity and suggest that the research agenda may be influenced by industry interests. The predominance of nutrient-specific topics in the nutrition research agenda could limit the public health relevance of rigorous evidence available for systematic reviews and dietary guidelines. More independent funding of nutrition research could address some of the imbalance in the research agenda. Effective nutrition policies need to be informed by evidence on a wider variety of interventions.

\section{Acknowledgements}

Financial support: This research received no specific grant from any funding agency in the public, commercial or not-for-profit sectors. Conflict of interest: L.A.B. is Co-Chair of the Cochrane Steering Group, for which The University of Sydney receives payment. Authorship: A.F., G.S. and L.A.B conceived the study and designed the data collection tool. A.F. and N.C. collected the data. A.F., N.C. and L.A.B. analysed the data. A.F. wrote the first draft of the paper. N.C., G.S. and L.A.B. contributed to the writing of the paper and approved the final version. Ethics of human subject participation: Not applicable.

\section{Supplementary material}

To view supplementary material for this article, please visit https://doi.org/10.1017/S1368980016003128

\section{References}

1. World Health Organization (2015) Non communicable diseases, Fact sheet. http://www.who.int/mediacentre/factsheets/fs355/ en/ (accessed May 2016).

2. World Health Organization (2015) Obesity and overweight, Fact sheet. http://www.who.int/mediacentre/factsheets/fs311/ en/ (accessed May 2016).

3. Brannon PM, Taylor CL \& Coates PM (2014) Use and applications of systematic reviews in public health nutrition. Annu Rev Nutr 34, 401-419.

4. Qaseem A, Snow V, Owens DK et al.; Clinical Guidelines Committee of the American College of Physicians (2010) The development of clinical practice guidelines and guidance statements of the American College of Physicians: summary of methods. Ann Intern Med 153, 194-199.

5. US Department of Health and Human Services (2015) Dietary Guidelines for Americans 2015-2020. http://health. gov/dietaryguidelines/2015/guidelines/ (accessed May 2016).

6. National Health and Medical Research Council (2011) A review of the evidence to address targeted questions to inform the revision of the Australian Dietary Guidelines. https://www.eatforhealth.gov.au/sites/default/files/files/the_ guidelines/n55d_dietary_guidelines_evidence_report.pdf (accessed May 2016).

7. Food Standards Australia New Zealand (2015) Reviews of foodhealth relationships for high level health claims. http://www. foodstandards.gov.au/consumer/labelling/nutrition/pages/ reviewsforhighlevelc3090.aspx (accessed May 2016).

8. Lawrence M, Naude C, Armstrong R et al. (2016) A Call to Action to reshape evidence synthesis and use for nutrition policy. Cochrane Library. http://www.cochranelibrary.com/ editorial/10.1002/14651858.ED000118 (accessed November 2016).

9. Odierna DH \& Bero LA (2009) Systematic reviews reveal unrepresentative evidence for the development of drug formularies for poor and nonwhite populations. J Clin Epidemiol 62, 1268-1278.

10. Lawrence M, Wingrove K, Naude C et al. (2016) Evidence synthesis and translation for nutrition interventions to combat micronutrient deficiencies with particular focus on food fortification. Nutrients $\mathbf{8}, 555$.

11. Pelletier DL, Porter CM, Aarons GA et al. (2013) Expanding the frontiers of population nutrition research: new questions, new methods, and new approaches. Adv Nutr 4, 92-114.

12. Marks JH (2014) Toward a systemic ethics of public-private partnerships related to food and health. Kennedy Inst Ethics J 24, 267-299.

13. Moodie R, Stuckler D, Monteiro C et al. (2013) Profits and pandemics: prevention of harmful effects of tobacco, alcohol, and ultra-processed food and drink industries. Lancet 381, 670-679.

14. Barnes D \& Bero L (1996) Industry-funded research and conflict of interest: an analysis of research sponsored by 
the tobacco industry through the Center for Indoor Air Research. J Health Polit Policy Law 21, 515-542.

15. Sismondo S (2008) How pharmaceutical industry funding affects trial outcomes: causal structures and responses. Soc Sci Med 66, 1909-1914.

16. Lundh A, Sismondo S, Lexchin J et al. (2012) Industry sponsorship and research outcome. Cochrane Database Syst Rev 12, MR000033.

17. Bero LA (2005) Tobacco industry manipulation of research. Public Health Rep 120, 200-208.

18. Kearns CE, Glantz SA \& Schmidt LA (2015) Sugar industry influence on the scientific agenda of the National Institute of Dental Research's 1971 National Caries Program: a historical analysis of internal documents. PLoS Med 12, e1001798.

19. Bes-Rastrollo M, Schulze MB, Ruiz-Canela M et al. (2013) Financial conflicts of interest and reporting bias regarding the association between sugar-sweetened beverages and weight gain: a systematic review of systematic reviews. PLoS Med 10, e1001578.

20. Kaiser KA, Cofield SS, Fontaine KR et al. (2012) Is funding source related to study reporting quality in obesity or nutrition randomized control trials in top-tier medical journals? Int J Obes (Lond) 36, 977-981.

21. Lesser LI, Ebbeling CB, Goozner M et al. (2007) Relationship between funding source and conclusion among nutritionrelated scientific articles. PLoS Med $\mathbf{4}$, e5.

22. Vartanian LR, Schwartz MB \& Brownell KD (2007) Effects of soft drink consumption on nutrition and health: a systematic review and meta-analysis. Am J Public Health 97, 667-675.

23. Foresight, Government Office for Science (2012) Tackling obesities: future choices - mid-term review (November 2008 to September 2010). https:/www.gov.uk/government/uploads/ system/uploads/attachment_data/file/288025/12-1210-tacklingobesities-mid-term-review.pdf (accessed July 2016).

24. Scrinis G (2013) Nutritionism. New York: Columbia University Press.

25. Tapsell LC, Neale EP \& Satija A (2016) Foods, nutrients, and dietary patterns: interconnections and implications for dietary guidelines. Adv Nutr 7, 445-454.

26. Jacobs DR \& Tapsell LC (2013) Food synergy: the key to a healthy diet. Proc Nutr Soc 72, 200-206.

27. Monteiro C (2011) The big issue is ultra-processing. There is no such thing as a healthy ultra-processed product. World Nutr 2, 333-349.

28. Drazen JM, Van Der Weyden MB, Sahni P et al. (2009) Disclosure of competing interests. BMJ 339, b4144.

29. International Committee of Medical Journal Editors (2009) Form for Disclosure of Potential Conflicts of Interests. http:// www.icmje.org/conflicts-of-interest (accessed July 2016).

30. Fardet A \& Rock E (2014) Toward a new philosophy of preventive nutrition: from a reductionist to a holistic paradigm to improve nutritional recommendations. Adv Nutr 5, 430-446.

31. Raubenheimer D, Machovsky-Capuska GE, Gosby AK et al. (2015) Nutritional ecology of obesity: from humans to companion animals. Br J Nutr 113, 26-39.
32. Cespedes EM \& Hu FB (2015) Dietary patterns: from nutritional epidemiologic analysis to national guidelines. Am J Clin Nutr 101, 899-900.

33. Williams PG (2014) The benefits of breakfast cereal consumption: a systematic review of the evidence base. Adv Nutr 5, 636-673.

34. Levy RB, Canella DS, Martins APB et al. (2013) Processed and ultra-processed food products and obesity in Brazilian households (2008-2009). Ann Nutr Metab 63 , 940-941.

35. Monteiro C, Levy R, Claro R et al. (2010) A new classification of foods based on the extent and purpose of their processing. Cad Saude Publica 26, 2039-2049.

36. Thornton M \& Schram M (1981) US holds the ketchup in schools. The Washington Post, 26 September. https:// www.washingtonpost.com/archive/politics/1981/09/26/ us-holds-the-ketchup-in-schools/9ffd029a-17f5-4e8c-ab911348a44773ee/ (accessed November 2016)

37. Peirson L, Douketis J, Ciliska D et al. (2014) Treatment for overweight and obesity in adult populations: a systematic review and meta-analysis. CMAJ Open 2, 306-317.

38. Oude Luttikhuis H, Baur L, Jansen H et al. (2009) Interventions for treating obesity in children. Cochrane Database Syst Rev issue 1, CD001872.

39. Schick SF \& Glantz SA (2007) Old ways, new means: tobacco industry funding of academic and private sector scientists since the Master Settlement Agreement. Tob Control 16, 157-164

40. Shawwa K, Kallas R, Koujanian S et al. (2016) Requirements of clinical journals for authors' disclosure of financial and non-financial conflicts of interest: a cross sectional study. PLOS ONE 11, e0152301.

41. Ruff K (2015) Scientific journals and conflict of interest disclosure: what progress has been made. Environ Health 14, 45.

42. Baethge C (2013) The effect of a conflict of interest disclosure form using closed questions on the number of positive conflicts of interest declared - a controlled study. Peer J 1, e128.

43. Forsyth SR, Odierna DH, Krauth D et al. (2014) Conflicts of interest and critiques of the use of systematic reviews in policymaking: an analysis of opinion articles. Syst Rev 3, 122 .

44. McCarthy M (2016) PubMed is urged to include competing interest information in abstracts. BMJ 353, i2018.

45. Roseman M, Turner EH, Lexchin J et al. (2012) Reporting of conflicts of interest from drug trials in Cochrane reviews: cross sectional study. BMJ 345, e 5155.

46. The Cochrane Collaboration (2013) Standards for the reporting of new Cochrane Intervention Reviews, Version 2.3. http:// editorial-unit.cochrane.org/mecir (accessed May 2016).

47. Hoffmann TC, Glasziou PP, Boutron I et al. (2014) Better reporting of interventions: template for intervention description and replication (TIDieR) checklist and guide. BMJ 34, g1687. 